\title{
SIMPLIFIED FRAGILITY ANALYSIS OF MULTI-SPAN ISOSTATIC RC-BRIDGES CONSIDERING AN INCOMPLETE KNOWLEDGE LEVEL
}

\author{
Andrea Nettis ${ }^{1}$, Domenico Raffaele ${ }^{1}$, Giuseppina Uva ${ }^{1}$ \\ ${ }^{1}$ Department of Civil, Environmental, Land, Building Engineering and Chemistry \\ Polytechnic University of Bari, Bari, Italy \\ e-mail: \{a.nettis, d.raffaele, g.uva\}@poliba.it
}

\begin{abstract}
The prediction of the seismic vulnerability of bridges is a challenging task for road managers which need to include structural risk prioritisation in their Bridge Management Systems. The large number of bridges designed without anti-seismic requirements and the uncertainties resulting from the lack of knowledge data (e.g. design documents and blueprints), strongly affect the feasibility of this process. A simplified approach for performing fragility analysis considering the epistemic uncertainty associated with an incomplete knowledge level is described. Uncertainties are considered through the statistical generation of a population of index-bridges, which are analysed utilizing a simplified modelling approach and the capacity method spectrum method applied with real ground-motion spectra. The proposed approach is applied on a case-study simply supported-girder RC bridge of the Basilicata provincial road network. The modelling and the influence of the epistemic uncertainty on the fragility are discussed for two knowledge levels corresponding to different data collection strategies. Finally, a validation of the proposed approach is carried out through a comparison with a refined modelling approach and non-linear dynamic analyses.
\end{abstract}

Keywords: fragility analysis, $\mathrm{RC}$ bridges, capacity spectrum method, nonlinear static procedures, seismic risk, cloud analysis. 


\section{INTRODUCTION}

Improving the safety of road networks is a challenging task for transportation infrastructure managers in natural-hazard-prone countries. In the aftermath of strong earthquakes, an inadequate seismic response of bridges may provoke direct and indirect losses, e.g. structural damages, economic losses or issues in managing post-event emergency. In most of the developed countries, the majority of the roadway/railway bridges were designed according to old regulatory codes lacking adequate anti-seismic design recommendations. For instance, in Italy, a high amount of bridges was built during the ' 60 s and '70s decades [1] when most of the Italian territory was not considered an earthquake-prone zone. Therefore, road managers have to deal with risk prioritization of large bridges portfolios, to identify structures that could exhibit poor performance in the aftermath of a seismic event. Low cost- and time-demanding analytical approaches for calculating fragility relationships and quantifying the risk of bridges are required.

In this context, many literature studies investigated the adoption of typological fragility assessment approaches for bridges (e.g. [2-5]). The HAZUS model [6] is a well-known reference on this topic. These simplified methodologies, based on a typological classification $[7,8]$ assume that the performance of bridges belonging to the same class is similar. One or more archetype structures, representative of each typological class, are identified and analysed to achieve class fragility curves, possibly considering the variability of geometrical/constructive characteristics within the class. The accuracy of these approaches is strictly linked to the classification scheme adopted, usually defined on a judgemental-empirical basis, that could not be directly related to the expected seismic performance [9]. Furthermore, typological approaches neglect structure-specific components and geometrical features that could be crucial in the vulnerability of bridges belonging to the same class (e.g. specific geometry, deck-pier connection type) [10].

On the other hand, recent studies focus on structure-specific approaches. Among them, simplified displacement-based assessment (DBA) algorithms are proposed and tested. Sadan et al. [11] proposed a simplified DBA approach for multi-span continuous girder RC bridges, which is recently refined by Gentile et al. [12,13] and Perdomo et al. [14]. Cardone [15] proposed displacement-based damage state thresholds for bridge components to be used within the DBA algorithm. These DBA approaches were also extended for simplified fragility function calculations by Cademartori et al. [16]. Stefanidou and Kappos [17] presented a hybrid methodology for bridge-specific fragility analysis suitable for bridge portfolio applications, using simplified elastic analysis. A different approach is adopted by Borzi et al. [18], that, by using a comprehensive database to store bridge data, developed an automated tool to build refined finite element models and to perform nonlinear time history analysis (NLTHA)-based fragility analysis for probabilistic seismic assessment within bridge portfolio applications.

Generally, within both a typological or structure-specific probabilistic seismic assessment framework, aleatory and epistemic uncertainties should be considered. These are respectively associated with the random nature of the seismic action or to the knowledge limit about mechanical properties (geometry, material etc.), modelling assumptions or capacity models. Epistemic uncertainties are modelled as random variables and appropriate statistical distribution. These are generally considered by statistical sampling techniques for generating a population of structures representative of the main one. This process burdens considerably the whole assessment procedure since multiplies the number of required analyses. A preliminary adequate knowledge level of the structure(s) being analysed could beneficially limit the number of uncertainties. However, a refined data collection phase may be unaffordable: on-site diagnostic inspections are time- and cost-consuming and bridge databases are lacking design data and blueprints which mostly were lost by management authority operators or stored into 
inaccessible archives. In the case of wide epistemic uncertainty, refined numerical models and analysis techniques are not a feasible solution and simplified fragility analysis methodologies should be applied.

In this study, a bridge-specific fragility analysis approach accounting appropriately for aleatory and epistemic uncertainties is proposed. The method adopts simplified mechanical models and capacity spectrum method (CSM) algorithms to perform cloud-based fragility analysis. The methodology aims to consider the uncertainty connected to the initial knowledge that particularly affects the seismic assessment of RC bridges when the input data are limited. Other types of epistemic uncertainties are neglected.

A refined description of the procedure, which currently is developed for multi-span isostatic (simply-supported) reinforced concrete (RC) bridges, is reported in Section 2. In Section 3, the procedure is applied to a case-study RC bridge for illustrative purpose. Preliminary validation of the simplified seismic performance assessment algorithm for fragility analysis is also provided using NLTHA as a benchmark.

\section{DESCRIPTION OF THE METHODOLOGY}

The simplified methodology to perform fragility analysis of bridges considering aleatory and incomplete-knowledge-based (hereinafter simply knowledge-based) uncertainties is described in this section. It resorts to simplified mechanical models, which are commonly used for the seismic analysis of isostatic multi-span bridges. A population of index-models is generated to consider the knowledge-based uncertainties, while the aleatory ones are represented by an appropriate suite of ground motions. The fragility analysis is performed by using a cloud approach for each index-model. A population of fragility curves representing the fragility of the main bridge can be thus generated and be used for simplified indicators of seismic risk. A synthetic flowchart is reported in Figure 1.

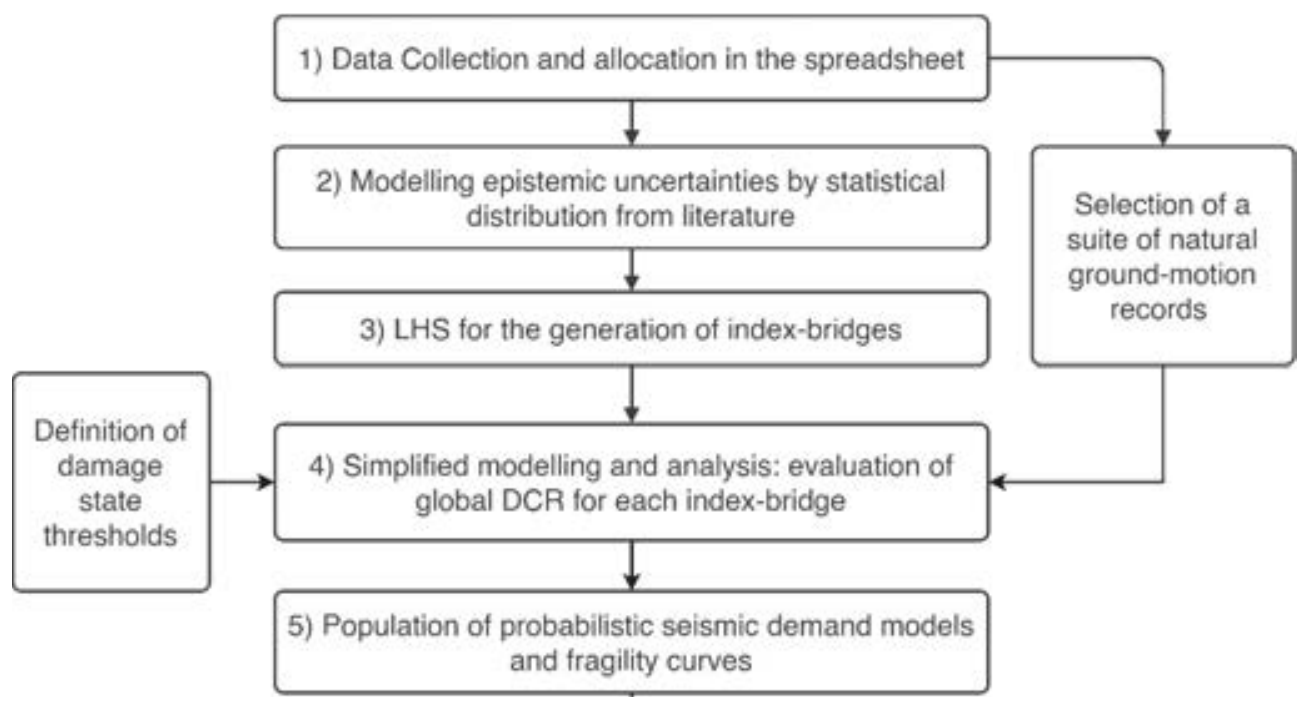

Figure 1: Flowchart of the proposed methodology

\subsection{Uncertainty modelling}

The first step of the methodology involves a data-collection process (Figure 1, step 1) that can be performed through fast in-situ inspections supported by innovative remote-sensing technologies such as drones equipped with optical sensors and photogrammetry algorithms. An example of how these new tools can be applied to effectively and quickly retrieve geometric 
and constructive data on bridges is reported in [19]. The completeness of the data collection can be affected by environmental constraints around the investigated bridge or by the proper constructive characteristics (e.g. inaccessible areas for natural obstacles or inability to collect images underneath the deck).

After this process, the knowledge-based uncertainties to be considered in the probabilistic seismic assessment can be identified (Figure 1, step 2). Geometry parameters, mechanical properties of the materials or the structural members, structural details, which are not assumed "deterministic", can be modelled as uncertainties and represented by random variables with appropriate statistical distributions. The latter can be identified based on literature studies. Zelaschi et al. [20] and Nielson et al. [21] proposed sets of statistical distributions to model appropriately the geometric parameters and the material properties of subclasses of highway bridges in Italy or the US, respectively. If literature references are not available, lacking data should be assumed based on engineering judgement. Furthermore, if more than one bridge is analysed within the same road network, lacking data on one bridge can be assumed for similarity with respect to the other bridges of the same typology within the same road network. Note that only engineering-relevant epistemic uncertainties should be modelled to avoid undesired burdening of the process. As anticipated, other types of epistemic uncertainty (e.g. the capacity models or for the definition of damage state thresholds), which are not considered in this study, can be similarly represented.

Epistemic uncertainties are usually modelled by introducing the random generation of a population of models (herein named index-bridges) "deterministically" characterised by variables selected from the corresponding statistical distributions by using statistical sampling techniques (Figure 1, step 3). To this aim, the standard or Latin Hypercube Sampling (LHS) Monte Carlo methodologies are generally used. The LHS [22] is widely used in literature for the probabilistic seismic analysis of both single or portfolios of bridges (e.g. [23,24]) and is usually preferred over the standard Monte Carlo technique since it requires less computational effort. In the LHS framework, the cumulative distributions of the random variables $X_{j}$ are divided into $\mathrm{N}$ equal probability intervals (stratification of the input), where $\mathrm{N}$ is the target number of realizations, and a single value is randomly extracted from each interval. The output samples are $\mathrm{N}$ vectors of size $j$, in turn, composed by values randomly paired under the assumption that these belong to different intervals. At the end of the sampling process, convergence in statistics should be checked to reach a number of models being representative of the real distribution and convenient in terms of computational effort. At the end of the simulation process, a set composed of $\mathrm{N}$ bridge realizations is obtained. Each realisation is "deterministically" characterised and can be directly analysed.

In addition to the knowledge-based uncertainty, the (aleatory) uncertainty linked to the random nature of the seismic action (i.e. record-to-record variability) should be modelled (Figure 1, step 4). In the proposed procedure, a cloud-based approach [25] is adopted to perform fragility analysis. To this aim, a wide suite of earthquake-induced ground motions representative of the seismic hazard condition of the site is needed. The selection of ground motions should be addressed reflecting the soil classification of the site and mean values of magnitude and distance of likely seismic events provided by an appropriate hazard deaggregation for the site of interest. Additional recommendations for the record selection are reported by Jalayer et al. [25].

\subsection{Simplified approach for seismic performance assessment}

In the following sub-section, the process for calculating the performance of the index-bridges under specific earthquake-induced ground motions, is described. Based on the fundamentals of 
nonlinear static procedures, equivalent single-degree-of-freedom (SDoF) capacity curves are attained analytically (in both longitudinal and transverse direction) and subjected to a capacity spectrum-based approach performed with real (un-smoothed) response spectra. Some assumptions of the proposed methodology are reported hereafter. Only the nonlinear response of the substructure members and the deck-substructure connection systems is considered, while the deck is supposed to respond elastically during the earthquake excitation. At this stage of the development, the foundations are modelled as fully-fixed constraints at the pier base according to $[18,26]$. However, the proposed procedure can be extended to account for soil-structure interactions following the methodology by $\mathrm{Ni}$ et al. [27]. The bi-directional effects of the seismic shaking are also neglected and each index-bridge is analysed separately in the transverse and longitudinal directions.

To reduce the necessary computational effort in analysing the index-bridges, a simplified seismic performance assessment strategy should be used within the procedure. The strategy proposed in this study is based on a simplified mechanical modelling approach suitable for multi-span isostatic bridges: the Individual Pier Model (IPM). However, it is worth mentioning that the general scheme of the proposed methodology (Figure 1) can be applied to other bridge typologies if suitable simplified modelling approaches are available (e.g. [28] for continuousdeck bridges). The IPM is a simplified strategy to analyse the seismic response of isostatic bridges with adjacent independent simply supported deck analysed in the transverse direction $[1,15,16]$. This approach is valid if relative rotations between the deck and the piers along the vertical axis are allowed. The seismic behaviour of each deck-pier/abutment subassembly can be analysed separately and can be represented by an equivalent SDoF multi-linear forcedisplacement law. This latter is obtained by combining the force-displacement relationships of the connection system (e.g. bearing devices, shear keys) and of the piers, assuming that these components act as a series system.

The force-displacement behaviour of single-column piers can be calculated according to $[29,30]$. To this aim, bilinear moment-curvature analyses are used, calculated by means of simplified surrogate meta-models [31,32] or programming routines [33]. The forcedisplacement law of framed piers can be achieved via simplified analytical methods based on mechanism analysis [34] or by simply aggregating the force-displacement laws of the columns acting in parallel in double-bending condition. If the flexibility of the bearings is negligible (i.e. fixed bearings) these can be assumed rigid and only the nonlinear behaviour of the pier is considered in the IPM. However, in most of the existing simply-supported bridges, the behaviour of the bearing devices should be considered. As an example, old fixed bearings (e.g. steel hinges or pin bearings) could experience brittle shear failures, followed by a pure friction (concrete-concrete) behaviour until deck-unseating phenomenon. Moreover, neoprene bearings were widely used in Italy between 1960 and 1990 [35] and can considerably affect the displacement profile of the IPM given their high deformability. Their shear strength is governed only by friction between rubber and concrete surfaces. The slipping of this type of bearings implies a nonlinear behaviour of the subassembly with large relative displacements between the deck and the pier. If present, the contribution of shear keys should be considered. Multilinear force-displacement laws for the mechanical characterisation of bearing devices and shear keys are reported in Cardone [15]. The cumulative force-displacement law of the deck-pier connection system can be attained by the sum of contribution of the bearing devices acting in parallel (i.e. the total base shear is the sum of the shear absorbed by the different devices subjected to the same top displacement).

The capacity curve of the equivalent SDoF representative of each subassembly can be calculated in a simplified way, assuming that its effective mass $\left(m_{s u b}\right)$ is entirely lumped in the centre of mass of the deck. Under the assumption of a series system, for a given value of the 
base shear $\left(V_{b}\right)$, the effective displacement of the equivalent $\mathrm{SDoF}$ system $\left(\Delta_{\text {sub }}\right)$ is given by the sum of the displacements of the pier $\left(\Delta_{\text {pier }}\right)$ and bearing system $\left(\Delta_{\text {bear }}\right)$, obtained by interpolating the respective constitutive laws at $V_{b}$.

To identify the performance of each subassembly under a specific ground-motion record the CSM [36] is applied. Particularly, the algorithm proposed by the authors [37] to apply the CSM with real spectra for fragility analysis is adopted. To this aim, the equivalent SDoF forcedisplacement law is converted in a capacity spectrum. The equivalent viscous damping of the subassembly $\left(\xi_{s u b}\right)$ associated with each value of $\Delta_{s u b}$ can be computed by Equation (1) aggregating the equivalent viscous damping of the pier $\left(\xi_{\text {pier }}\right)$ and the deck-pier connection system $\left(\xi_{\text {bear }}\right)$. For each $\xi_{\text {sub }}$, the spectral reduction factor $\eta_{\text {sub }}$ can be calculated to compute overdamped spectra and to identify the performance point (PP). To calculate $\xi_{\text {pier }}$ and $\xi_{\text {bear }}$ the ductility-based formulations by Priestley et al. [29] can be applied. At the end of this process, the seismic performance of each subassembly under a given seismic action can be calculated.

$$
\xi_{\text {sub }}=\frac{\Delta_{\text {pier }} \xi_{\text {pier }}+\Delta_{\text {bear }} \xi_{\text {bear }}}{\Delta_{\text {sub }}}
$$

The IPM can be used to analyse the response of the bridge in the longitudinal direction if the width of the expansion joints between adjacent decks allows for relative displacement between the subassemblies. This approach is usually suitable for bridges where the expansion joints between the independent decks are seismically designed: each subassembly responds independently until the closure of the joints is reached. In this case, the tributary seismic mass of each subassembly is strictly influenced by the type of bearing devices (fixed or free) and their capacity to transfer shear forces.

Conversely, if a premature closure of the joints is expected (e.g. non-seismically designed joints, designed for thermal dilatations only) or in presence of shock-transmitters, the bridge subassemblies act as a parallel system. In this case, the subassemblies resist a portion of the global seismic action depending on the proper (secant-to-top-displacement) stiffness. If the closure of the deck-abutment joint is expected, the abutment-backfill interaction should be appropriately considered in the simplified model [5]. The force-displacement relationships related to an equivalent SDoF of the entire bridge is calculated: the force-displacement laws of each deck-pier subassembly are aggregated, assuming that all the subassemblies are subjected to the same deck displacement (only one degree of freedom) which is axially rigid. Given a predetermined target displacement of the deck, the shear force in each subassembly can be achieved by interpolating the corresponding force-displacement laws. These are summed up to calculate the total base shear. Repeating this process for incremental control node displacement, the equivalent SDoF capacity curve is obtained. For each step, the equivalent viscous damping $\left(\xi_{\text {eff }}\right)$ is calculated via Equation (2) where $N$ is the total number of $i$ subassemblies. The capacity curve is thus subjected to the CSM [37] to calculate the PP.

$$
\xi_{\text {eff }}=\frac{\sum_{i=1}^{N} \xi_{\text {sub }, i} V_{\text {sub }, i}}{\sum_{i=1}^{N} V_{\text {sub }, i}}
$$

\subsection{Methodology for fragility analysis}

After the calculation of the performance demand for each index-bridge subjected to each of the selected ground-motion records, the fragility analysis is performed. Fragility curves express the probability to reach or exceed a damage state (DS) conditioned to a given value of seismic 
intensity. Note that fragility analysis of complex systems, like bridges, composed of multiple components, is not a straightforward task, since, the DS of the bridge is related to the DS of the different members (e.g. piers, bearings, abutments). The proposed procedure requires the analyst to define DS thresholds for each bridge member depending on the number of limit states of interest. Recommendations for defining DS thresholds for RC components, bearing devices, shear keys, etc are reported by Cardone [15]. Deterministic DS thresholds are defined in this procedure. However, the uncertainty on the DS thresholds should be easily accounted for according to e.g. [3,23].

The system fragility is defined based on the DS of the different components. In this study, the bridge is simply considered a series system and the weakest member determines the DS of the bridge [25]. The performance of each $i$-th bridge component (e.g. pier, bearing system, abutment) under the $j$-th ground motion with respect to a given DS, is expressed by a Demand Capacity Ratio ( $D C R$ ) calculated with Equation (3). The global bridge $D C R_{j}$ related to the $j$-th ground-motion record is the maximum of the $D C R_{i, j}$ of the different $i$-th components. As an example, if only the piers, the bearings and the abutments are considered as critical components, the global $D C R_{j}$ is given by Equation (4) where the $p, b$ and $a b$ subscripts indicate piers, bearings and abutments, respectively.

$$
\begin{gathered}
D C R_{i j}^{D S}=\frac{\Delta_{i j}}{\Delta_{i}^{D S}} \\
D C R_{j}^{D S}=\max \left(D C R_{p 1, j}^{D S}, \ldots, D C R_{p N, j}^{D S}, D C R_{b 1 j}^{D S}, \ldots, D C R_{b N j}^{D S}, D C R_{a b 1 j}^{D S}, D C R_{a b 2 j}^{D S}\right)
\end{gathered}
$$

Various literature studies focus on the definition of optimal intensity measures (IM) for probabilistic seismic analysis of bridges. The appropriate type of IM should be chosen

depending on the scope of the application with reference to its efficiency, sufficiency, practicality and hazard computability. An in-depth study about this is reported in e.g. [21,38].

In this study, fragility functions represent the probability that (the "weakest" member of) the index-bridge reaches a unitary DCR given a determined value of IM and are calculated via a cloud analysis approach [28]. Firstly, the results of the previous analyses are organized in couples of $I M_{j}-D C R_{j}$ (i.e. the "cloud data" ). It is assumed that a power-law model ( $D C R=$ $a I M^{b}$ ) best expresses the relationship between the structural demands and IM [39]. The parameter $[a, b]$ are estimated fitting a linear model to the cloud data transformed in the natural logarithmic scale using the least square method. This is expressed by Equation (5) where $\alpha_{D C R \mid I M}$ represents the median DCR (50\% to be exceeded) conditioned to the IM value for a given DS. The dispersion of the demand around the median estimated with the regression model is assumed constant varying the IM and is given Equation (6) where $\mathrm{M}$ is the number of ground motion records. Once, $\alpha_{D C R \mid I M}$ and $\beta_{D C R \mid I M}$ are calculated (simply $\alpha$ and $\beta$ hereinafter), the fragility function, $P(D C R>1 \mid I M)$, and can be expressed by Equation (7) where $\phi(\cdot)$ is the standard cumulative distribution functions (CDF).

$$
\begin{gathered}
\ln (D C R)=\ln \alpha_{D C R \mid I M}=\ln (a)+b \ln (I M) \\
\beta_{D C R \mid I M}=\sqrt{\frac{\sum_{j=1}^{M}\left(\ln D C R_{j}-\ln a\left(I M_{j}\right)^{b}\right)}{M-2}}
\end{gathered}
$$




$$
P(D C R>1 \mid I M)=\phi\left(\frac{\ln \alpha_{D C R \mid I M}}{\beta_{D C R \mid I M}}\right)=\phi\left(\frac{\ln a(I M)^{b}}{\beta_{D C R \mid I M}}\right)
$$

Following this approach, the obtained fragility function is calculated for each index-bridge accounting for demand uncertainty only (i.e. record-to-record variability). The influence of the knowledge-based uncertainty is represented by the variability within the entire dataset of fragility curves related to the index-bridges. This population of fragility curves can be synthesized using specific percentiles of the dataset of the medians and the dispersions [40].

A synthetic fragility curve comprehensive of both aleatory and epistemic uncertainty can be defined by calculating the median $\alpha_{\text {bridge }}$ for a given DS as the median of the population of $\alpha_{k}$ related to the $k$-th index-bridges with Equation (7). The overall dispersion ( $\left.\beta_{\text {bridge }}\right)$ should account for both the dispersion of the fragility curves of the single index-models $\left(\beta_{k}\right)$ and the dispersion around the medians. These contributions are combined with the SRSS rule.

For risk-based prioritisation purposes, the seismic risk and its variability linked to epistemic uncertainty can be calculated. As an example, the simplified strategies by [41] can be used to calculate the mean annual frequency of exceeding a determined DS $\left(\lambda_{D S}\right)$.

$$
\begin{gathered}
\ln \alpha_{\text {bridge }}=\left(\sum_{k=1}^{N} \ln \alpha_{k}\right) / N \\
\beta_{\text {bridge }}=\sqrt{\left(\frac{1}{N} \sum_{k=1}^{N} \beta_{k}\right)^{2}+\left(\frac{1}{N} \sum_{k=1}^{N} \ln \alpha_{k}-\ln \alpha_{\text {bridge }}\right)^{2}}
\end{gathered}
$$

\section{APPLICATION OF THE PROPOSED METHODOLOGY TO A CASE-STUDY BRIDGE}

The proposed framework is applied on a case-study bridge, part of the Basilicata provincial road-network. Two time- and cost-saving approaches are used to perform the data collection, leading to two different levels of knowledge about the geometrical and constructive features of the bridge. The following sections describe the data collection approach, the modelling of uncertainties and the results of the fragility analysis. This section aims to practically describe how to apply the proposed algorithm dealing with real bridges and provide a preliminary validation of the adopted simplified mechanical modelling strategy in fragility analysis.

\subsection{Description of the bridge, data collection approaches and uncertainties}

The main features of the case-study bridge are reported in Figure 2. The bridge exhibits an isostatic structural scheme with five $30 \mathrm{~m}$-long spans. The superstructure is composed of simply supported independent adjacent decks consisting of precast RC girders having a I-shaped cross section. The height of the single-column piers, having circular cross section (diameter equal to $2.60 \mathrm{~m}$ ) ranges between 6.6 and $13.6 \mathrm{~m}$. Although the exact year of design is unknown, it is assumed that the bridge was built between the 1980-1984 and designed according to the D.M. 3 marzo 1975 and D.M. 2 agosto 1980 [42,43] for seismic and bridge traffic loads, respectively. Note that this information can be easily retrieved from road managers' databases or, if necessary, modelled as knowledge-based uncertainty as follows.

The data collection is performed according to two data collection methodologies. The first exploits open-source Google Earth Street View data and a dataset of images collected on-site and is indicated hereinafter as low-knowledge level (KL1). The geometry was characterized by 
means of image processing and measurements by GE data and images. The second data collection approach uses imagery collected by a drone-based survey and photogrammetric elaborations and is identified as high-knowledge level. Further information about this dronebased data collection methodology is reported in [19]. A (Excel-based) data-form is used to store the information in a suitable format to be directly used by a sequence of programming routines developed in MATLAB [44]. These routines perform the statistical sampling for modelling uncertainty and the simulated design of columns (sub-section 2.1) and the fragility analysis according to the simplified mechanics-based approach (sub-sections 2.2 and 2.3).

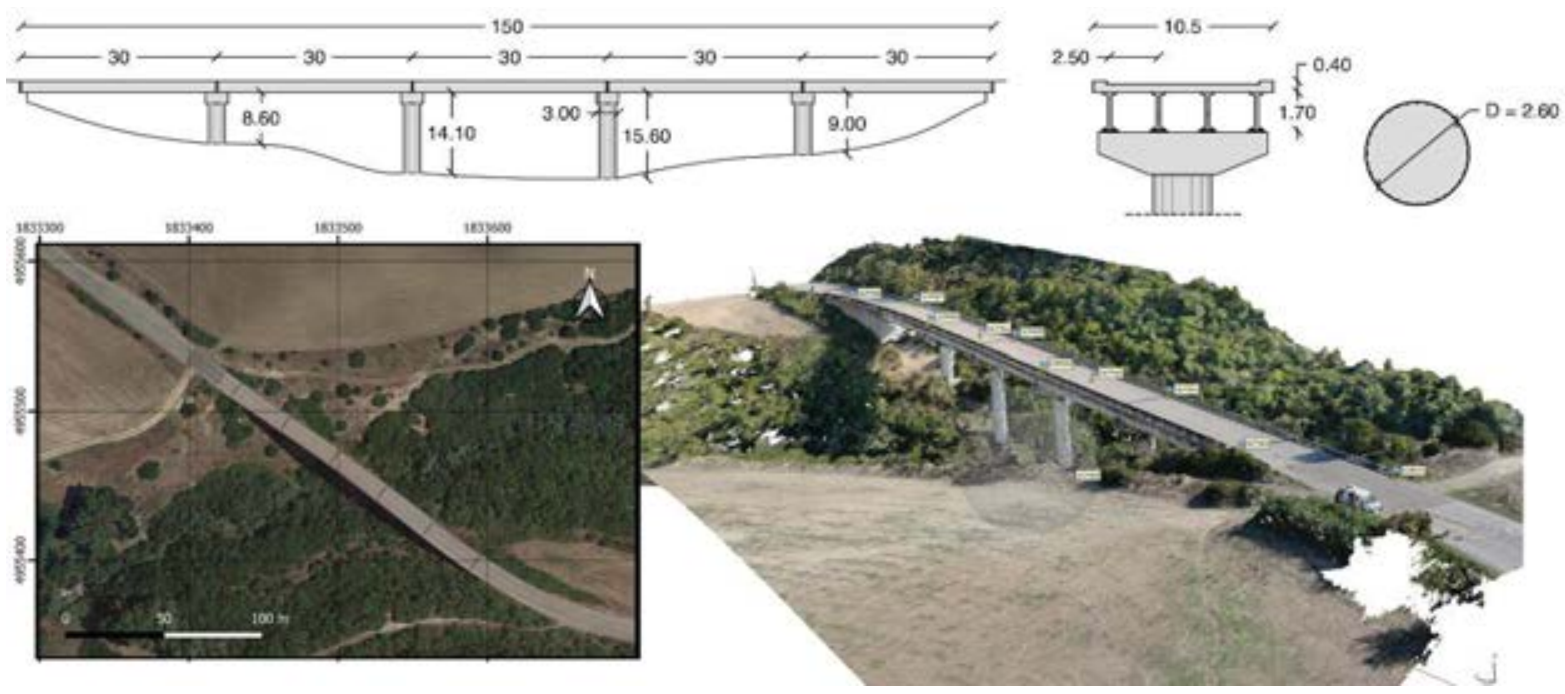

Figure 2: Geometric and constructive characterization of the case-study bridge [19].

Table 1 lists the uncertainties defined via some statistical distributions derived from literature studies $[3,20,23,24,45]$ and engineering judgement. For parameters whose statistical distributions are not available, the maximum uncertainty is assumed using a uniform distribution (continuous or discrete) [40]. Although statistical distributions from different contexts (e.g. United States) are used, it is expected that more data about Italian highway bridges will be available in future, improving the reliability of such an approach. Table 1 differentiates the uncertainties associated with low- and high- knowledge levels (KL1 and KL2). With reference to KL1, no information on the typology of the bearing devices placed between the superstructure and the pier caps is detected. Therefore, in addition to the parameters listed in the table, the variability of two configurations of bearing typology are assumed: fixed/free bearings and neoprene bearings. In the first configuration, the bearings are assumed to be fixed in the transverse direction, while a fixed and a movable bearing line is placed on the top of each pier in longitudinal direction. Also, a variability between three and four devices per bearing line (two lines in total) is assumed. The width of the expansion gaps is low and not measurable at this knowledge level. It is assumed varying according to [3,23] and confirmed by [16] for not seismically designed Italian bridges. Conversely, the KL2 allows for identifying that the deck cross-section is composed of four precast girders (thus four devices per bearing line) and neoprene bearings of $4 \mathrm{~cm}$-thickness; the gap size between the deck and abutments is fixed at $2.5 \mathrm{~cm}$.

The variability in the design class of the materials $\left(f_{c k}\right.$ and $\left.f_{y k}\right)$ is modelled. Mean and dispersion of the mean strength values of concrete and steel $\left(f_{c k}\right.$ and $\left.f_{y k}\right)$ are calculated depending on the characteristic values assuming a coefficient of variation of 0.09 and 0.18 [24]. 
The LHS is performed to generate the population of models. For each model, the longitudinal reinforcement layout is calculated by means of a simulated design procedure. An appropriate MATLAB routine was developed to perform this task according to Italian old regulatory codes for bridges. The procedure automatically neglects the couples of design concrete and steel classes which lead to an incompatible design with respect to the old reference code. Since in the '70-'90 decades, the design of transverse reinforcements of bridge columns was dictated by constructive needs rather than mechanical because of the low seismic design actions the volumetric ratio of the transverse reinforcement $\left(\rho_{t}\right)$ is modelled with a uniform distribution (Table 1).

The uncertainty about the seismic action is considered via an appropriate ground-motion suite. A dataset of 100 natural ground-motion records is selected from the SIMBAD database [46] consistently with the characteristic of soil type [47], magnitude and distance of expected earthquakes in the site. The magnitude and distance de-aggregation is achieved using the software Rexel [48]. The ground motions compatible with these requirements are firstly collected (176 ground motions). Then, the 100 records with the highest PGA (geometric mean of the two directions) were selected to perform the fragility analysis. The PGA of the selected record varies between 1.77 and $0.16 \mathrm{~g}$.

\begin{tabular}{|c|c|c|c|c|}
\hline Parameter & Knowledge Level & Distribution & Distr. Param. & \\
\hline $\begin{array}{l}\text { Characteristic compressive } \\
\text { concrete strength }\left(f_{c k}\right)\end{array}$ & KL1-KL2 & Uniform (Discrete) & $25-30-35$ & $\mathrm{MPa}$ \\
\hline $\begin{array}{l}\text { Characteristic tensile steel } \\
\text { strength }\left(f_{y k}\right)\end{array}$ & KL1-KL2 & Uniform (Discrete) & $375-440$ & $\mathrm{MPa}$ \\
\hline $\begin{array}{l}\text { Mean concrete compressive } \\
\text { strength }\left(f_{c m}\right)\end{array}$ & KL1-KL2 & Normal & $\mu=1, \sigma=0.18$ & Factor \\
\hline Mean steel Tensile Strength $\left(f_{y m}\right)$ & KL1-KL2 & Normal & $\mu=1, \sigma=0.09$ & Factor \\
\hline $\begin{array}{l}\text { Transverse reinforcement } \\
\text { volumetric ratio }\left(\rho_{t}\right)\end{array}$ & KL1-KL2 & Uniform & $0.05-0.1 *$ & $\%$ \\
\hline Abutment gap size & KL1 & Normal & $\mu=24.5, \sigma=5$ & $\mathrm{~mm}$ \\
\hline $\begin{array}{l}\text { Shear modulus of neoprene } \\
\text { bearings }(G)\end{array}$ & KL1-KL2 & Uniform & $1=0.8, u=1.2$ & $\mathrm{MPa}$ \\
\hline $\begin{array}{l}\text { Thickness of neoprene bearings } \\
\left(t_{b}\right)\end{array}$ & KL1 & Uniform & $1=40, u=70$ & $\mathrm{~mm}$ \\
\hline Abutment passive stiffness & KL1-KL2 & Uniform & $1=0.5, u=1.5$ & Factor \\
\hline Mass variability $(\mathrm{G} 1+\mathrm{G} 2)$ & KL1 & Uniform & $1=0.9, \mathrm{u}=1.1$ & Factor \\
\hline
\end{tabular}

Table 1: Variability in geometrical/constructive bridge characteristics depending on the knowledge level (KL)

\subsection{Modelling assumptions and damage states}

Once the models are completely characterised, the seismic assessment is performed according to the CSM-based procedure (sub-section 2.2). To this aim, the moment-curvature relationships of the piers are calculated using CUMBIA [33]. This analysis shows that the flexure governs the seismic behaviour and damage state of the piers. An elastic perfectly-plastic behaviour is assigned to the neoprene bearings, assuming that the maximum strength is reached for slipping between the neoprene and the concrete surfaces, as suggested by Cardone [15] for low-thickness neoprene bearings. The stiffness of each neoprene bearing device is equal to $k_{b}=G A / t_{b}$ ( $\mathrm{G}$ is the shear modulus, $\mathrm{A}$ is the area of the pad) and the slipping strength is calculated assuming a friction coefficient $(\mu)$ equal to 0.4 . The flexibility of the fixed bearings is neglected together with their shear failure (i.e. it is implicitly assumed that the maximum shear of the subassembly is reached before the shear failure of the fixed bearings). Finally, the 
longitudinal response of the abutment-backfill systems for seat type abutments is calculated as proposed in $[49,50]$, while its transverse deformability is neglected.

To provide validation for the simplified performance assessment approach, the bridge is also analysed by means of NLTHA performed in Opensees [51]. A refined numerical modelling strategy is adopted in this case. The RC-piers are modelled via BeamWithHinges elements composed of an internal elastic part and a nonlinear hinge at the base. The Hysteretic material is used to model the nonlinear cyclic behaviour of the plastic hinges, expressed by means of a sectional moment-curvature law. The deck and the pier caps are represented by elastic beam elements. TwoNodesLink elements are utilised to capture the nonlinearity of the bearing devices (elastic-perfectly-plastic material) and the abutment-backfill interactions (impact material). A tangent stiffness proportional damping is defined for NLTHA [29]. Moreover, a 5\% Rayleigh damping model is assigned.

An overview of the local damage state thresholds used to compute the DCR for each component is reported in Table 2 . The most damaged component determines the global damage state. The thresholds correspond to slight damage (DS1), severe damage (DS2) and collapse prevention (DS3).

\begin{tabular}{|c|c|c|c|c|}
\hline Element & DS1 & $\mathrm{DS} 2$ & DS3 & Note \\
\hline Piers (flexural) & $\Delta_{y}$ & $\Delta_{y}+2 / 3\left(\Delta_{u}-\Delta_{y}\right)$ & $\Delta_{u}$ & $\begin{array}{l}\Delta_{y} \text { and } \Delta_{u} \text { are the yielding and ultimate } \\
\text { displacement of the pier. }\end{array}$ \\
\hline Neoprene & & & & $\begin{array}{l}\Delta_{f r}=\left(\mu P / k_{b}\right) \text { is the displacement corresponding } \\
\text { to the friction strength attainment, } P \text { is the }\end{array}$ \\
\hline $\begin{array}{l}\text { bearings } \\
\text { (slipping) }\end{array}$ & $\Delta_{f r}$ & $\Delta_{p a d}$ & $\Delta_{\text {uns }}$ & $\begin{array}{l}\text { compressive load of the bearing device. } \Delta_{\text {pad }} \text { is the } \\
\text { dimension of the bearing device in the considered } \\
\text { direction. } \Delta_{\text {uns }} \text { corresponds to deck unseating }\end{array}$ \\
\hline Sliding bearings & - & - & $\Delta_{\text {uns }}$ & $\begin{array}{l}\Delta_{s l} \text { is the displacement capacity of the bearing } \\
\text { device }\end{array}$ \\
\hline $\begin{array}{l}\text { Abutment- } \\
\text { backfill system }\end{array}$ & $\Delta_{\text {gap }}$ & $\Delta_{p b w}$ & $1.1 \Delta_{p b w}$ & $\begin{array}{l}\Delta_{p b w} \text { is the displacement at the reaching of passive } \\
\text { backfill pressure calculated starting from } k_{b w}= \\
k_{i} w(h / 1.7) \text { and } P_{b w}=h_{w} w p_{i}(h / 1.7), \text { where } h \\
\text { and } w \text { are the height and width of the abutment } \\
\text { backwall, } k_{i} \text { is equal to } 11.5(\mathrm{kN} / \mathrm{mm}) \mathrm{m} \text { and } p_{i} \text { is } \\
239 \mathrm{kPa} \text {. }\end{array}$ \\
\hline
\end{tabular}

Table 2: Damage state thresholds for each considered components

\subsection{Convergence in the statistics}

Reaching convergence in random sampling is essential for the accuracy of the final fragility estimations. This section aims at identifying the number of index-bridges in the population necessary to achieve robustness in the results, to ensure that the addition of other samples does not involve strong modifications of the final results. This is necessary to identify a sample size which reflects a compromise between computational effort (more index-models, more calculations) and representativeness of the generated population (more index-models, higher accuracy). For this task, the KL1 is considered, where an higher influence of uncertainties is expected with respect to the KL2 case.

First, a first sampling is performed, producing a population of 500 index-bridges. This dataset is analysed, calculating the corresponding set of 500 fragility curves. For this task, PGA is used as IM and DS3 is only considered. A dataset of medians of the fragility curves are collected and their $50^{\text {th }}$ percentile $\left(\alpha_{\text {opt }}\right)$ is extracted and assumed as an optimal estimation of the median IM associated with the fragility of the whole population. The $10^{\text {th }}$ and $90^{\text {th }}$ 
percentiles are calculated also, providing optimal estimates of the variability in the median IM of the population leading DS3.

This process is repeated several times reducing the sampling size ( $N_{s}=$ $[200,100,50,25,15])$. The stability of the counterparts $\left(\alpha_{N S}\right)$ with respect to the optimal values is evaluated calculating the relative errors. Figure 3 reports that errors within a range of $10 \%$ are achieved when a sample size of 50 realisations is selected. Clearly, this result is strongly related to the adopted uncertainties for this selected bridge, and further studies should investigate the sample size varying the expected influence of the uncertainty.

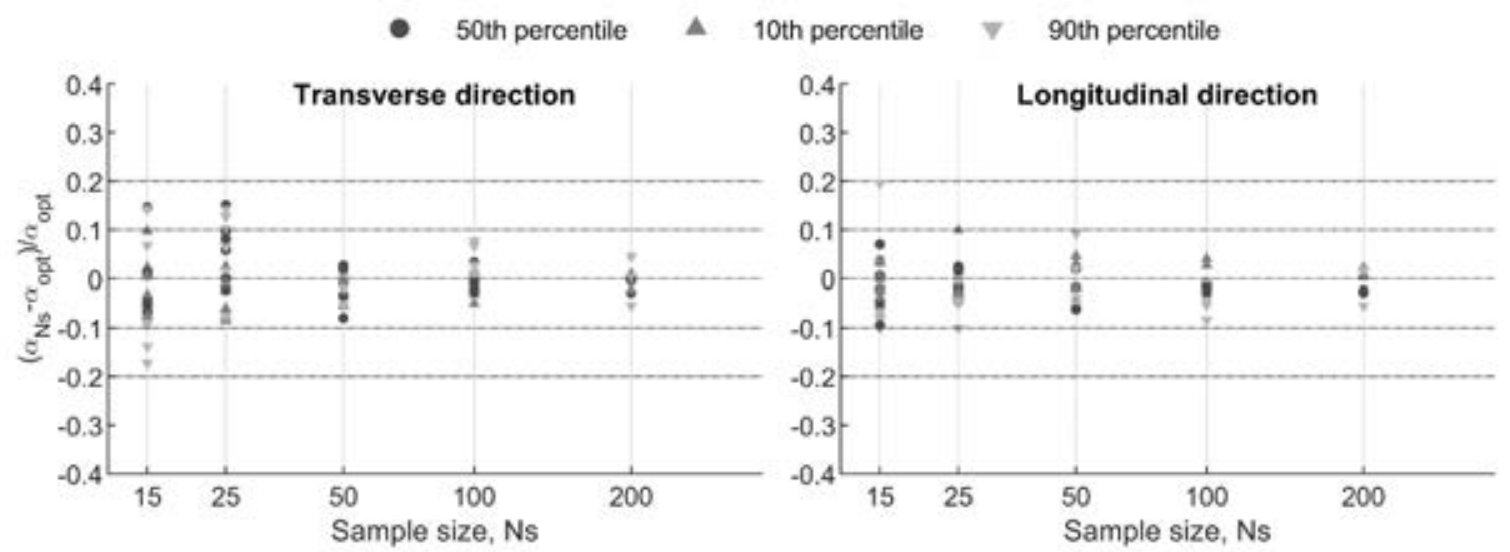

Figure 3: Relative errors on $50^{\text {th }}, 10^{\text {th }}$ and $90^{\text {th }}$ of the median IM with respect to the sample size

\subsection{Discussion on results}

In this subsection, the results of the fragility analysis are discussed to evaluate the influence of the incomplete knowledge level and the reduction of this effect due to a reduction of the general uncertainty. Also, the errors induced by the simplified analysis approach with respect to refined NLTHA are evaluated. The results are numerically listed in Table 3 and graphically shown in Figure 4. Particularly, Table 3 reports the values of the median IM (i.e. PGA) associated with the $50^{\text {th }}$ percentile of the fragility population (Eq. (8)) and the per cent relative difference $\left(\operatorname{err}_{D S}^{10 / 90 t h}=\left(\alpha_{D S}^{10 / 90 t h}-\alpha_{D S}^{50 t h}\right) / \alpha_{D S 1}^{50 t h} * 100\right)$ of the $10^{\text {th }}$ and $90^{\text {th }}$ percentile with respect to the $50^{\text {th }}$ one to numerically evaluate the influence of uncertainties. These per cent differences are represented by the amplitude of the "bundle" in Figure 4 representing synthetically the fragility curve population. As expected, the influence of a low-knowledge level, quantified by the $10^{\text {th }}$ and $90^{\text {th }}$ percentiles, is strongly reduced with a more accurate data collection. This effect is noticeable for the transverse direction, while it is slighter for the longitudinal where the damage is governed by the abutment-backfill interaction that is less affected by the uncertainties. In the transverse direction, the $10^{\text {th }}$ and $90^{\text {th }}$ percentiles of the median IM of the population change in a range which reaches $[-50 ;+50] \%$ of the $50^{\text {th }}$ percentiles regardless of the DS.

Figure 5 better explains this outcome, showing the population of fragility curves for the KL1 case at DS2 (chosen for illustrative purposes). Red curves correspond to index-bridges having fixed/free bearings, while blue ones indicated index-bridges where neoprene bearings are present. Moreover, the pattern of the curve is related to the critical member which reaches DS, i.e. pier (flexure), bearing device or abutment-backfill system. Figure 5a shows that in the transverse direction, the variability in critical member induces wide variability in fragility curve parameters. The group of index-bridges with neoprene bearings (red) are generally associated with lower fragility (lower probability of reaching DS) than the index-bridges where fixed bearings are present and piers are damaged for flexure. The neoprene bearings produce a beneficial effect in the vulnerability in the transverse direction, since their slipping prevents 
further increase of shear force in the piers, enhancing the ductility of the bearing-pier subassemblies. This outcome is consistent with [18]. This explains the general increase in $\alpha_{D S}^{50 t h}$ for KL2, where only neoprene bearings are modelled, with respect to KL1 (Table 3). In this case, the maximum variability of $\alpha_{D S}$ is registered at DS3 and corresponds to the range [-30.48; $+13.81] \%$.

\begin{tabular}{lccccccccc}
\hline Case & $\alpha_{D S 1}^{50 t h}$ & $\operatorname{err}_{D S 1}^{10 t h}$ & $\operatorname{err}_{D S 1}^{90 t h}$ & $\alpha_{D S 2}^{50 \text { th }}$ & $\operatorname{err}_{D S 2}^{10 t h}$ & $\operatorname{err}_{D S 2}^{90 \text { th }}$ & $\alpha_{D S 3}^{50 t h}$ & $\operatorname{err}_{D S 3}^{10 t h}$ & $\operatorname{err}_{D S 3}^{90 t h}$ \\
\hline KL1-CSM & 0.64 & -41.62 & 49.77 & 1.34 & -40.59 & 49.01 & 2.05 & -39.98 & 49.15 \\
KL2-CSM & 0.82 & -24.09 & 12.77 & 1.66 & -28.70 & 12.91 & 2.33 & -30.48 & 13.81 \\
KL2-NLTHA & 0.80 & -19.07 & 11.67 & 1.58 & -24.11 & 11.64 & 2.38 & -28.46 & 19.99 \\
\hline & \multicolumn{7}{c}{ Longitudinal direction } \\
\hline KL1-CSM & 0.26 & -34.95 & 31.05 & 0.71 & -20.44 & 28.47 & 0.78 & -23.65 & 35.99 \\
KL2-CSM & 0.24 & -7.57 & 5.24 & 0.64 & -13.74 & 34.59 & 0.68 & -14.29 & 36.81 \\
KL2-NLTHA & 0.25 & -5.86 & 3.66 & 0.67 & -12.90 & 36.23 & 0.71 & -13.61 & 37.91 \\
\hline
\end{tabular}

Table 3: Median PGA $\left(50^{\text {th }}\right)$ and per cent shift associated with $10^{\text {th }}$ and $90^{\text {th }}$ percentiles
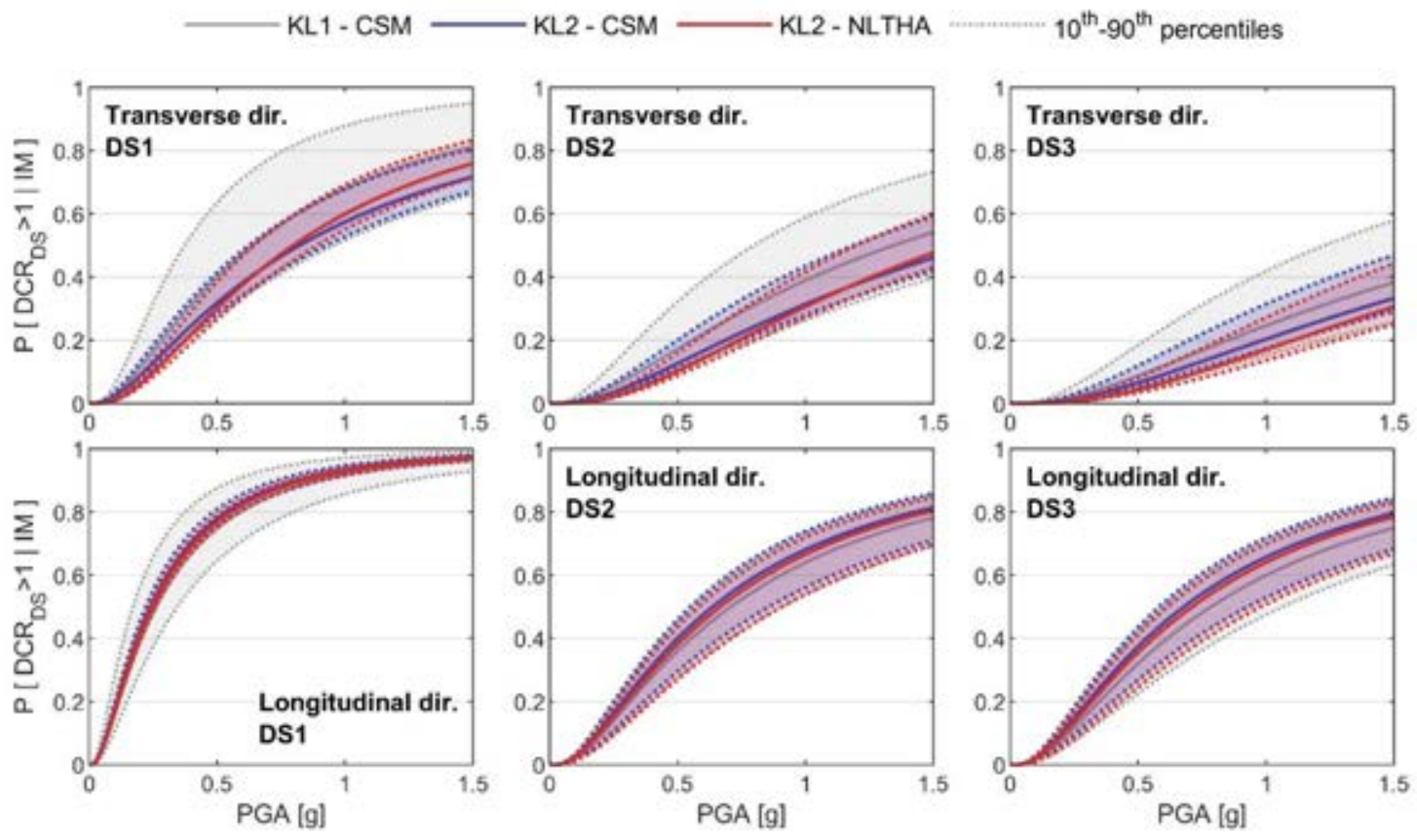

Figure 4: Fragility curves and associated variability for the case-study bridge considering the KL1 (analysed via CSM) and KL2 (analysed via CSM and NLTHA).

A shown in Figure 5b, in the longitudinal direction, it is very common among the analysed index-bridges that the abutment-backfill system induces the DS2. This is confirmed by [5] for non-seismically designed bridges. The presence of neoprene bearings is unfavourable for the fragility of the case-study bridge in this case. Indeed, the index-bridges where fixed bearings are present exhibit a lower probability to be damaged since the piers collaborate with the abutment-backfill system in resisting the total amount of seismic action. Conversely, neoprene bearings decrease the stiffness of the deck-pier subassemblies inducing a higher amount of seismic action directly transferred to the abutment and anticipating the reaching of DS2. It is 
observed that in the longitudinal direction, the $\alpha_{D S}$ ranges in a narrower interval with respect to the transverse direction.

Figure 4 evidences the general accuracy provided by the simplified CSM for fragility analysis with respect to NLTHA. In this case, the relative error between the two approaches on the median IM of the fragility curves $\left(50^{\text {th }}\right.$ percentile) is lower than $5 \%$ regardless of the DS and the analysis direction. This evidences that, for this case study, the assumptions of the simplified IPM, that neglects the interactions between the subassemblies, and the equivalent viscous damping strategy is appropriate. However, this should be considered as a first outcome and other tests are needed for other case-study bridges or using more efficient IM in the calculation of fragility curves,

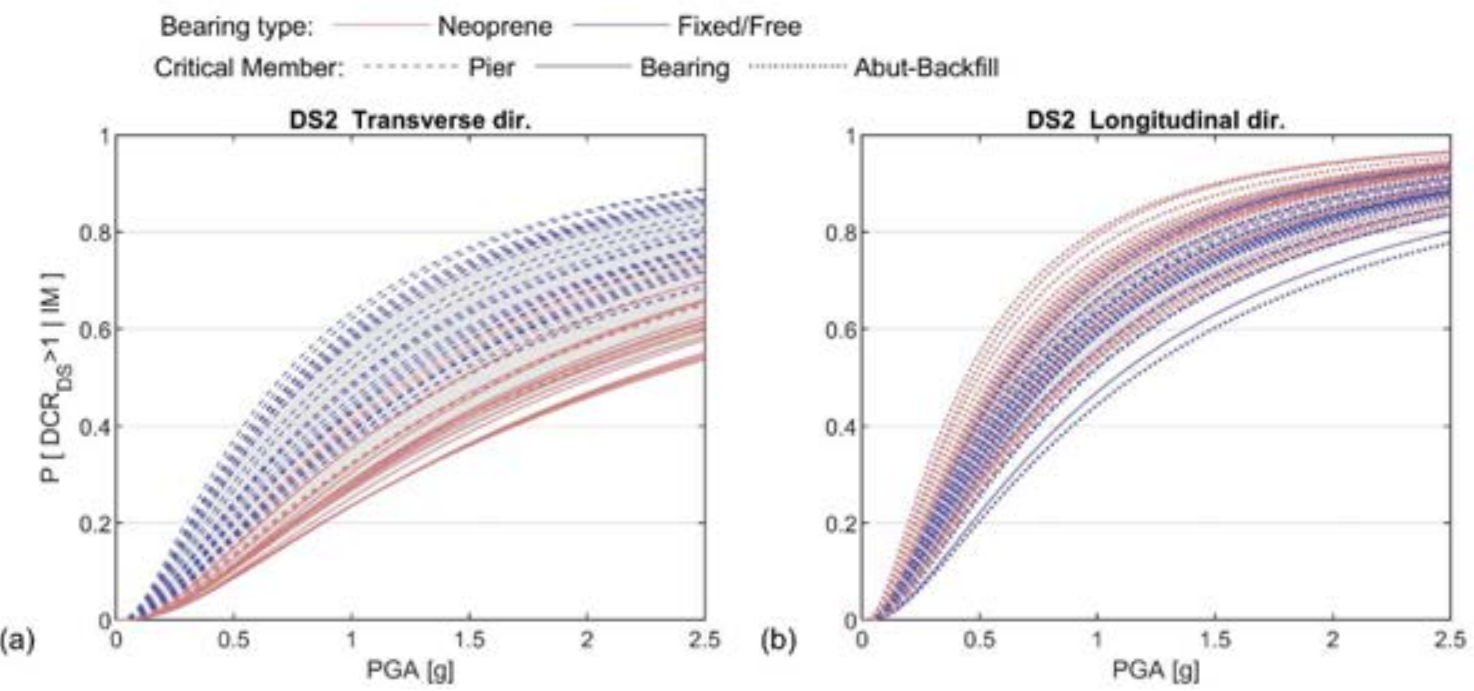

Figure 5: Population of fragility curves for the KL1 case at DS2. Different colours aim to distinguish the bearing type of the index-bridge, different patterns indicate different critical members. The grey area indicated the area between the $10^{\text {th }}$ and the $90^{\text {th }}$ percentiles.

\section{CONCLUSIONS}

In this study, a simplified methodology to perform fragility analysis of bridges directly accounting for uncertainties linked to an incomplete knowledge level is described. These knowledge-based uncertainties are considered by means of the statistical generation of a population of index bridges. The analysis of index-bridges is based on a simplified modelling approach, suitable for isostatic typical Italian bridges, and the capacity spectrum method used to evaluate the performance of index-bridges under a specific earthquake record. The performance of the single index-bridge is synthesized by a set of Demand-Capacity Ratios which is used to fit regression-based probabilistic seismic demand models and compute fragility curves. The fragility of the main bridge is represented by a population of fragility curves and the influence of knowledge-based uncertainties can be quantified by extracting significant percentile values of the population.

The proposed approach is applied on a case-study bridge of the Basilicata (Italy) provincial road network. The case-study section is aimed at illustrating the different steps of the procedure. Two data collection approaches are performed using different data sources involving two knowledge levels characterised by different degree of completeness. The case-study section tests the appropriate sample size to generate a representative population of index-bridges and provide a validation of the simplified analysis approach by means of the comparison with nonlinear time history analysis on a refined numerical model. The fragility analysis shows that the response of the abutment-backfill system in the longitudinal direction is decisive for the 
fragility of this case study whose deck-abutment gap size is not seismically designed. In the transverse direction, the fragility of the bridge is affected by the bearing typology and the lack of this information strongly increases the influence of the uncertainties. It can be stated that an adequate preliminary data collection should address the width of the abutment-deck gap and the typology of the deck abutment connections. The employment of typological approaches that neglect thes components could involve severe inaccuracies in fragility estimations of bridge portfolios.

Finally, it is worth mentioning that further validations are needed to investigate the accuracy of the simplified fragility analysis methodology for different bridge types as continuous deck bridges.

\section{ACKNOWLEDGEMENTS}

The research presented in this paper was partially funded by the Italian Department of Civil Protection in the framework of the national project DPC-ReLUIS 2019-2021.

\section{REFERENCES}

[1] Pinto PE, Franchin P. Issues in the upgrade of Italian highway structures. J Earthq Eng 2010;14:1221-52. https://doi.org/10.1080/13632461003649970.

[2] Choi E, DesRoches R, Nielson B. Seismic fragility of typical bridges in moderate seismic zones. Eng Struct 2004. https://doi.org/10.1016/j.engstruct.2003.09.006.

[3] Nielson BG, DesRoches R. Seismic fragility methodology for highway bridges using a component level approach. Earthq Eng Struct Dyn 2007. https://doi.org/10.1002/eqe.655.

[4] Avşar Ö, Yakut A, Caner A. Analytical fragility curves for ordinary highway bridges in Turkey. Earthq Spectra 2011. https://doi.org/10.1193/1.3651349.

[5] Moschonas IF, Kappos AJ, Panetsos P, Papadopoulos V, Makarios T, Thanopoulos P. Seismic fragility curves for greek bridges: Methodology and case studies. Bull Earthq Eng 2009. https://doi.org/10.1007/s10518-008-9077-2.

[6] FEMA. Multi-Hazard Loss Estimation Methodology, Earthquake Model, Hazus ${ }^{\circledR}-\mathrm{MH}$, Technical Manual. 2003.

[7] Zelaschi C, Monteiro R. Towards a Taxonomy for Portuguese Rc Bridges 2017:65262. https://doi.org/10.7712/120117.5447.17003.

[8] Hancilar U, Taucer F. Guidelines for typology definition of European physical assets for earthquake risk assessment - SYNER-G Reference Report 2. 2013. https://doi.org/10.2788/68751.

[9] Mangalathu S, Jeon J-S, Padgett JE, DesRoches R. Performance-based grouping methods of bridge classes for regional seismic risk assessment: Application of ANOVA, ANCOVA, and non-parametric approaches. Earthq Eng Struct Dyn 2017. https://doi.org/10.1002/eqe.2919.

[10] Stefanidou SP, Kappos AJ. Bridge-specific fragility analysis: when is it really necessary? vol. 17. Springer Netherlands; 2019. https://doi.org/10.1007/s10518-01800525-9. 
[11] Şadan OB, Petrini L, Calvi GM. Direct displacement-based seismic assessment procedure for multi-span reinforced concrete bridges with single-column piers. Earthq Eng Struct Dyn 2013. https://doi.org/10.1002/eqe.2257.

[12] Gentile R, Nettis A, Raffaele D. Effectiveness of the Displacement-Based seismic performance Assessment for continuous RC bridges and proposed extensions. Eng Struct 2020;in press:110910. https://doi.org/10.1016/j.engstruct.2020.110910.

[13] Nettis A, Gentile R, Uva G, Raffaele D. Validation of an analytical displacement-based pushover for multi-span continuous deck bridges. COMPDYN Proc., 2019.

[14] Perdomo C, Monteiro R. Extension of displacement-based simplified procedures to the seismic loss assessment of multi-span RC bridges. Earthq Eng Struct Dyn 2020. https://doi.org/10.1002/eqe.3389.

[15] Cardone D. Displacement limits and performance displacement profiles in support of direct displacement-based seismic assessment of bridges. Earthq Eng Struct Dyn 2014. https://doi.org/10.1002/eqe.2396.

[16] Cademartori M, Sullivan TJ, Osmani S. Displacement - based assessment of typical Italian RC bridges. Bull Earthq Eng 2020. https://doi.org/10.1007/s10518-020-008619.

[17] Stefanidou SP, Kappos AJ. Methodology for the development of bridge-specific fragility curves. Earthq Eng Struct Dyn 2017;46:73-93.

https://doi.org/10.1002/eqe.2774.

[18] Borzi B, Ceresa P, Franchin P, Noto F, Calvi GM, Pinto PE. Seismic Vulnerability of the Italian Roadway Bridge Stock. Earthq Spectra 2014.

[19] Nettis A, Saponaro M, Nanna M. RPAS-based framework for simplified seismic risk assessment of Italian RC-bridges. Buildings 2020.

https://doi.org/10.3390/BUILDINGS10090150.

[20] Zelaschi C, Monteiro R, Pinho R. Parametric Characterization of RC Bridges for Seismic Assessment Purposes. Structures 2016;7. https://doi.org/10.1016/j.istruc.2016.04.003.

[21] Padgett JE, Nielson BG, DesRoches R. Selection of optimal intensity measures in probabilistic seismic demand models of highway bridge portfolios. Earthq Eng Struct Dyn 2008. https://doi.org/10.1002/eqe.782.

[22] Olsson A, Sandberg G, Dahlblom O. On Latin hypercube sampling for structural reliability analysis. Struct Saf 2003. https://doi.org/10.1016/S0167-4730(02)00039-5.

[23] Tavares DH, Padgett JE, Paultre P. Fragility curves of typical as-built highway bridges in eastern Canada. Eng Struct 2012;40:107-18. https://doi.org/10.1016/j.engstruct.2012.02.019.

[24] Monteiro R. Sampling based numerical seismic assessment of continuous span RC bridges. Eng Struct 2016;118:407-20. https://doi.org/10.1016/j.engstruct.2016.03.068.

[25] Jalayer F, Ebrahimian H, Miano A, Manfredi G, Sezen H. Analytical fragility assessment using unscaled ground motion records. Earthq Eng Struct Dyn 2017;46:2639-63. https://doi.org/10.1002/eqe.2922.

[26] Calvi GM, Pinto PE, Franchin P. Seismic design practice in Italy. In: Chen W-F, Duan 
L, editors. Bridg. Eng. Handb. 2nd Ed. Seism. Des., CRC-Press; 2013.

[27] Ni P, Petrini L, Paolucci R. Direct displacement-based assessment with nonlinear soilstructure interaction for multi-span reinforced concrete bridges. Struct Infrastruct Eng 2014;10:1211-27. https://doi.org/10.1080/15732479.2013.802813.

[28] Nettis A, Gentile R, Uva G, Raffaele D. SOME APPLICATIONS OF A DISPLACEMENT-BASED PROCEDURE FOR THE SEISMIC RESPONSE OF CONTINUOUS GIRDER RC-BRIDGES. 3rd Int. Conf. Int. Conf. Recent Adv. Nonlinear Des. Resil. Rehabil. Struct. (CoRASS 2019), 2019.

[29] Priestley MJN, Calvi GM, Kowalsky MJ. Displacement-based seismic design of structures. IUSS Press, Pavia, Italy; 2007.

[30] Raffaele D, Porco F, Fiore A, Uva G. Simplified vulnerability assessment of reinforced concrete circular piers in multi-span simply supported bridges. Struct Infrastruct Eng 2014;10:950-62. https://doi.org/10.1080/15732479.2013.772642.

[31] Gentile R, Porco F, Raffaele D, Uva G. Simplified moment-curvature relationship in analytical form for circular RC sections. Bull New Zeal Soc Earthq Eng 2018;51:14558 .

[32] Gentile R, Raffaele D. Simplified analytical Moment-Curvature relationship for hollow circular RC cross-sections. Earthq Struct 2018;15:419-29. https://doi.org/10.12989/eas.2018.15.4.419.

[33] Montejo LA, Kowalsky MJ. Set of codes for the analysis of reinforced concrete members. Environ Eng 2007.

[34] Gentile R, del Vecchio C, Pampanin S, Raffaele D, Uva G. Refinement and Validation of the Simple Lateral Mechanism Analysis (SLaMA) Procedure for RC Frames. J Earthq Eng 2019:1-29. https://doi.org/10.1080/13632469.2018.1560377.

[35] Tortolini P, Petrangeli M, Lupoi A. Criteri per la verifica e la sostituzione degli appoggi in neoprene di viadotti esistenti in zona sismica. 14th Ital. Conf. Seism. Eng., Bari: 2011.

[36] Freeman SA. Development and use of capacity spectrum method. Proc. 6th U.S. Natl. Conf. Earthq. Engng., Seattle: CD-ROM, EERI, Oakland; 1998.

[37] Nettis A, Gentile R, Raffaele D, Uva G, Galasso C. Cloud Capacity Spectrum Method: accounting for record-to-record variability in fragility analysis using nonlinear static procedures. (Under Rev Soil Dyn Earthq Eng n.d.

[38] Zelaschi C, Monteiro R, Pinho R. Critical Assessment of Intensity Measures for Seismic Response of Italian RC Bridge Portfolios. J Earthq Eng 2017. https://doi.org/10.1080/13632469.2017.1342293.

[39] Cornell CA, Jalayer F, Hamburger RO, Foutch DA. Probabilistic basis for 2000 SAC federal emergency management agency steel moment frame guidelines. J Struct Eng 2002. https://doi.org/10.1061/(ASCE)0733-9445(2002)128:4(526).

[40] Celik OC, Ellingwood BR. Seismic fragilities for non-ductile reinforced concrete frames - Role of aleatoric and epistemic uncertainties. Struct Saf 2010;32:1-12. https://doi.org/10.1016/j.strusafe.2009.04.003.

[41] Dolšek M. Simplified method for seismic risk assessment of buildings with 
consideration of aleatory and epistemic uncertainty. Struct Infrastruct Eng 2012;8:93953. https://doi.org/10.1080/15732479.2011.574813.

[42] Decreto Ministro dei Lavori Pubblici (DM) 3 marzo 1975 -Approvazione delle norme tecniche per le costruzioni in zone sismiche. G.U. 8-4-1975, n.93; 1975.

[43] Decreto Ministeriale (DM) 2 agosto 1980 - Criteri Generali e prescrizioni tecniche per la progettazione, esecuzione e collaudo dei ponti 1980.

[44] The MathWorks Inc. MATLAB . version 9.5.0.944444 (R2018b) 2018.

[45] Cardone D, Perrone G, Sofia S. A performance-based adaptive methodology for the seismic evaluation of multi-span simply supported deck bridges. Bull Earthq Eng 2011. https://doi.org/10.1007/s10518-011-9260-8.

[46] Smerzini C, Galasso C, Iervolino I, Paolucci R. Ground motion record selection based on broadband spectral compatibility. Earthq Spectra 2014;30:1427-48. https://doi.org/10.1193/052312EQS197M.

[47] Forte G, Chioccarelli E, De Falco M, Cito P, Santo A, Iervolino I. Seismic soil classification of Italy based on surface geology and shear-wave velocity measurements. Soil Dyn Earthq Eng 2019;122. https://doi.org/10.1016/j.soildyn.2019.04.002.

[48] Iervolino I, Galasso C, Cosenza E. REXEL: Computer aided record selection for codebased seismic structural analysis. Bull Earthq Eng 2010. https://doi.org/10.1007/s10518-009-9146-1.

[49] Caltrans. Seismic Design Criteria Version 1.7. Calif Dep Transp Sacramento, CA, US 2013.

[50] Sextos A, Mackie K, Stojadinovic B, Taskari O. Simplified P-y relationships for modeling embankment-abutment systems of typical Calfornia bridges. 14th World Conf. Earthq. Eng. Beijing, China, 2008.

[51] McKenna F. OpenSees: A framework for earthquake engineering simulation. Comput Sci Eng 2011. https://doi.org/10.1109/MCSE.2011.66. 